Amris \& Williams[Query-Q2: Alma Dabral(CE) to All(AU)]It is our house style to italicize genes to differentiate them from proteins. Can you please check and confirm that any genes in your article are italicized correctly?

[Query-Q3: Alma Dabral(CE) to All(AU)]It is our house style to leave all proteins, genes and growth factors in their abbreviated form only. Please could you ensure none of these have been defined (including the figures and tables of articles)?Managing chronic pain in survivors of torture

Special Report

Managing chronic pain in survivors of torture

Kirstine Amris ${ }^{*}$ \& Amanda C de C Williams ${ }^{2}$

${ }^{1}$ The Parker Institute, Department of Rheumatology, Copenhagen University Hospital, Bispebjerg \& Frederiksberg, Copenhagen, Nordre Fasanvej 57, DK-2000 Frederiksberg, Denmark

${ }^{2}$ Research Department of Clinical, Health \& Educational Psychology, University College London, London, UK

*Author for correspondence: kirstine.amris@regionh.dk[Query-Q4: Alma Dabral(CE) to All(AU)]Please check all author names and details are presented correctly (including the running header at the top of the page).

\begin{abstract}
All generalist and specialist clinicians are likely to encounter torture survivors among refugees and asylum seekers. A minority of people survive torture and a smaller minority reach a developed country; those who do tend to be the more resilient and resourceful. They have many health, social and welfare problems; persistent pain in the musculoskeletal system is one of the most common. There is little specific evidence on pain in survivors of torture; the guidelines on interdisciplinary specialist management are applicable. Most of the literature on refugee survivors of torture has an exclusive focus on psychological disorders, with particularly poor understanding of pain problems. This article summarizes the current status of assessment and treatment of pain problems in the torture survivor.
\end{abstract}

Keywords:

- falanga $\bullet$ post-torture pain $\bullet$ torture $\bullet$ torture methods $\bullet$ torture rehabilitation $\bullet$ torture survivor $\bullet$ torture victim

Practice points

- Clinicians are key in identifying survivors of torture and need to be proactive in this. 
- The experience of pain in survivors of torture is associated with a wide range of psychological and social consequences that need to be addressed.

- The commonest presentation is persistent pain in the musculoskeletal system, and headache.

- Symptoms frequently associated with pain are poor sleep and fatigue (particularly with widespread pain), significant distress, cognitive dysfunction and visceral disturbance.

- There are few studies of pain mechanisms in survivors of torture but changes in spinal or supraspinal pain modulation are central in the persistence of pain.

- The optimal treatment approach is interdisciplinary, multimodal with a focus on agreed goals of understanding the meaning of pain, and improving function, mood and participation.

Torture is understood by international law as the intentional infliction of severe mental or physical pain or suffering by or with the consent of the state authorities for a specific purpose (United Nations:[1]). [QueryQ5: Sankeetha Nadarajah(PE) to All(AU)]References have been renumbered in numerical order of citation (refs 54/55 appeaered early in the article).Despite many countries being signatories to the UN Convention, torture remains a widespread practice which is maintained by widespread impunity for perpetrators. Torture is directed against individuals and their political, ethnic, religious, language and other communities. Challenging torture entails not only asylum and access to healthcare and welfare, which some developed countries provide, albeit with restrictions, but also rehabilitation and reparation for the individual. Beyond that, challenging torture entails challenging perpetrators and bringing them to justice. Health professionals can promote all these aims, consistent with the explicit commitments of many of their national and international professional bodies. Recognizing the multifaceted problems of torture survivors referred for treatment, and acknowledging the relationship between rehabilitation and prevention, significantly broadens the remit of healthcare professionals around the aims of reparation: restitution, compensation, rehabilitation, satisfaction and guarantees of nonrepetition; this therefore includes public recognition of the criminal acts and ideally trial and punishment of perpetrators.

The right to reparation is part of international legal standards (UN Declaration of Human Rights article 14) states that "each State party shall ensure redress and adequate compensation, including rehabilitation". The aim is to restore, as far as possible, torture survivors' independence; their physical, mental, social and vocational ability; and to facilitate full inclusion and participation in society. In order to do this, each State party should adopt a long-term, integrated approach in which specialist services for survivors of torture or illtreatment are available, appropriate and readily accessible [2]. This is not yet realized anywhere in the world.

Pain is central to torture, but inadequately recognized among the long-term consequences [3], with little consensus on how it should be addressed $[4,5]$. Because distress is usually substantial and often evident in those seeking healthcare, pain has often been subsumed under the associated symptoms of disorders such as chronic post-traumatic stress (PTSD), depression or other psychological problems [6]. This is based on a lack of understanding of chronic pain and results in the failure to address possibly treatable physical pain [79]. This article focuses on healthcare, specifically on pain problems in the survivor of torture, using an explicitly biopsychosocial model of pain [10].

\section{Forms of torture}

Torture aims to destroy a human by the systematic infliction of severe pain, brutalization and psychological cruelty. Torture methods are often somewhat illogically classified as physical or psychological methods, when in most cases, the victim is exposed to a combination of forms of torture - both physical and psychological - 
and it has been argued that fear and helplessness-inducing effects may be a major determinant of perceived severity of methods of torture [11]. In addition, imprisonment often includes inadequate food and water, exhaustion and debility through sleep deprivation, isolation from communication with any but the captors and monopolization of perception. In many cases, victims' families are threatened, and they themselves suffer mock executions or witness or are forced to participate in the torture and maltreatment of other prisoners or family members $[3,12-16]$.

Physical torture is in many countries directed toward methods that will leave no specific findings after the acute stage. Soft tissue lesions and pain result from random beatings, systematic beating (head, palms, soles and lumbar region), strapping/binding and suspension by the extremities, forced positions for extended periods of time and electrical torture. Other methods include asphyxiation, near drowning, stabbing, cutting, burning and sexual assaults including hetero- and homosexual rape $[3,12-16]$.

The identification of torture survivors in the clinical encounter

Healthcare professionals are very likely to encounter torture survivors as refugees and asylum seekers but not to recognize them [17-19]. One review [3] suggests that, when patients are from persecuted minorities in countries where torture occurs, the clinician should suspect torture when the patient presents chronic multiple pains, multiple physical scars or complex injuries; another study suggests that musculoskeletal pain, headaches or depression, anxiety or PTSD symptoms in refugees should suggest the possibility of torture [17].

Disclosure of torture is difficult for many reasons. Survivors may be convinced that nobody will believe their story, or will reject them. The health professional hesitates to ask, often because of uncertainty about the survivor's reaction. Where both clinician and survivor are silent about the trauma, it is hard to make sense of the patient's presentation. It is therefore imperative to establish trust and to ask directly about exposure to physical or psychological assaults, including specific torture methods. The invitation to disclose is usually a relief for the patient and demonstrates respect and concern.

Special considerations may be necessary in assessment and treatment of torture survivors. Distrust resulting from torture may extend to health professionals, not least since officials such as prison doctors may have been involved in the torture situation [20,21]. Flashbacks are intrusive memories that result in re-experiencing a traumatic event, sometimes to the extent of losing contact with present reality, can be provoked by events reminiscent of the torture situation: medical equipment, uniforms, waiting, waking from unconsciousness (e.g., anesthesia) and other events and cues. The risk of flashbacks is minimized by a calm atmosphere, detailed explanations of planned procedures, obtaining fully informed consent and facilitating the patient's control over procedures.

Professional interpreters (where possible, not family members or untrained heathcare personnel) are often needed, not only to translate what the survivor and clinician say to one another, but also as cultural guides for both. Neutrality and professional confidentiality of the interpreter are crucial and should be explained to the torture survivor.

The torture survivor who is a refugee and asylum seeker has additional problems which complicate presentation, assessment and treatment: uncertainty about civil status; unstable accommodation or homelessness; isolation from family, community and even others speaking the same language; anxiety about family and friends in the country she/he fled; poverty; racism; and hostility in the host society [22]. Detention in the host country is associated with serious deterioration in mental health [23].

Pain \& pain-related problems in survivors of torture

The experience of torture is associated with a wide array of chronic health problems, of which pain and pain- 
related disability are dominant. Most studies of torture survivors are set in specialized documentation and/or treatment centers, and indicate high prevalence of persistent pain, with overall estimates as high as $78-83 \%$ $[13,16,24]$. Although one study comparing survivors seen within 2 weeks of torture with those seen later indicated some spontaneous resolution of pain [25], a follow-up study of survivors in Denmark showed increased prevalence of chronic pain over the intervening 10 years [26]. An increase in pain and associated disability has also been reported in a recent Danish study of traumatized asylum seekers assessed at arrival and 10 months later [27]. Although multiple pains and widespread pain are common [16,28], particularly headache and musculoskeletal pain [3,16,29-32], the best studied pain problems associated with specific methods of torture are foot pain from falanga (falaka), and shoulder and upper limb pain from hanging by the arms.

Falanga, beating of the soles, is commonly reported by torture survivors [33]. It leaves no gross signs long term, but is characterized by a neuropathic burning and stinging pain in the sole; sensory and autonomic changes; a dull deep pain in the feet on weight bearing, spreading up the lower leg with walking and eased by rest [33-35]; increased pain on rest after activity; and distorted gait and avoidance of weight bearing. All these can seriously affect daily activities [35]. Scars and/or pigmentations in the soles may be evident [33], and reduced elasticity in the foot pads on palpation, loosening of the skin, soreness and coating of the plantar fascia and sensory disturbances in the soles appears to be characteristic although not pathognomonic [36]. MRI [37] and Doppler examination [38] identified thickening of the plantar aponeurosis but not the muscle compartment syndrome anticipated or thinning of the heel pad. Quantitative sensory testing suggests some small fiber neuropathy $[39,40]$.

Suspension by the arms, especially with the arms tied behind the back, the shoulder joint maximally extended and inwardly rotated (also unjustly called Palestinian hanging), strains and injures the shoulder joint and surrounding soft tissues. A typical presentation is of pain in the shoulder, upper arm and neck; weakness and fatigue in the arm; sensory changes; restricted movement and a sensation of looseness and instability in the shoulder joint. Clinical findings are mostly not specific; a few systematic studies of the possible mechanisms underlying long-term pain and associated symptoms have proposed overload injuries of the shoulder joint, such as injuries of the glenoid labrum, joint capsule and ligaments; and partial lesions of the brachial plexus [31].

Pain mechanisms in chronic post-torture pain

Despite contributions from forensic and accident medicine, we have little understanding of the effects of many forms of torture. The concepts of pain syndromes evolving over time, predicted by the severity, extent and repetition of the original trauma, are presumed to apply to post-torture pain syndromes, but studies are lacking. Careful documentation and studies of survivors are beginning to establish connections between some forms of torture and persistent pain, better described by mechanism than by site.

Pain originating in peripheral nociceptors may be caused by: permanent injury in the musculoskeletal system, such as lesion of the shoulder joint after suspension by the upper extremities, lesion of the knees caused by direct blows or forced prolonged knee-loading positions, or lesion of plantar structures after falanga; and/or strain in the musculoskeletal system secondary to overload and disuse due, for instance, to joint dysfunction and compensatory altered posture, movement or gait.

Traumatic nerve lesion caused by blows, strangulation, traction and other forces are probably common in survivors of torture, and neuropathic pain therefore a likely pain mechanism. Neuropathic pain syndromes have been described in survivors of torture based on the clinical presentation: neuropathic pain in the feet after falanga, neuropathic pain due to partial lesion of the brachial plexus after suspension by the upper extremities; 
partial lesion of the lumbosacral plexus after suspension by the lower extremities; segmental, radiating pain after forced, back-loading positions; trigeminal neuralgia after head trauma; and peripheral neuropathy after tight binding of wrists or ankles [9,31-32,41].

Contemporary research demonstrates a highly integrated pain system such that pathological pain states usually involve central pain processing changes as well as changes in neuroimmune, neuroendocrine and autonomic nervous system regulation [42]. Central sensitization and dysfunction of descending pain modulating systems are implicated in several chronic muscular pain syndromes from torture: regional or widespread pain often associated with poor sleep, fatigue, cognitive impairment, headache and visceral symptoms, variously diagnosed in other settings as chronic widespread pain, fibromyalgia and polysymptomatic functional syndromes. Unsuccessful attempts to match subjective pain reports to objective findings, in the context of unfamiliarity with chronic pain mechanisms among healthcare professionals, and evident psychological distress in the survivor are used to support psychosomatic theories of pain, even when torture has been disclosed and documented. Better sense of this type of pain is made using understanding of changes in pain signaling in the CNS in the context of prolonged high levels of pain and distress [7].

\section{Psychological problems common in survivors of torture}

Since torture targets the person as a whole [43], survivors present a wide range of psychological difficulties which are not well described in conventional diagnostic categories $[44,45]$, and which occur in a context of social and legal difficulties. There is considerable evidence to support the activity of mechanisms of psychological distress in amplifying pain, compromising adaptation to pain and acting as a stressor, thereby causing worsened distress. Alongside chronic pain, it is common for survivors to have symptoms of PTSD, anxiety, depression and other distress [46], including outbreaks of anger and violence directed toward family members [44], guilt (including about survival) and shame. Torture has particular personal meanings, which only the survivor can describe. Previous life experience and cultural differences also affect the consequences of torture [47], and current circumstances, particularly uncertainty about asylum, financial hardship, social isolation and separation from or loss of family and roles and other problems related to their circumstances, all contribute to current psychological problems and exacerbate existing ones $[48,49]$.

Treatment studies tend to select by diagnosis and deliver treatment by protocol, producing changes, if any, which fall far short of recovery [50]. Ideally, treatment would also be informed by a human rights context, by cultural differences in the expression of distress and help-seeking, and would take account of the personal meaning of torture. The main treatments for PTSD are cognitive behavioral therapy, and narrative exposure therapy [51]. Cognitive behavioral therapy often includes exposure, and a normalizing educational component, while narrative exposure therapy draws on testimony writing [52,53]. Treatment efficacy overall is disappointing [50], and the practice of exposure is problematic in torture survivors $[53,54]$.

\section{Management of torture survivors \& chronic post-torture pain}

Biopsychosocial models, integrating physical, psychological and social-contextual factors in the total experience of pain, have been instrumental in the development of multidisciplinary and multimodal treatment regimes for chronic pain. The impact of torture, uprooting and a life in exile on psychological and social health is described above; all factors of which may have a negative influence on behavioral and cognitive aspects of pain and pain-related disability, treatment feasibility and outcome of healthcare. Furthermore, the lack of studies of the treatment of physical problems from torture, particularly of pain, means that recommendations amount to good clinical practice applied sensitively to patients who may be seriously traumatized, and attempts to rehabilitate from injuries $[5,55]$. In the clinic, failure to appreciate the complex interrelationship between trauma-related problems and chronic pain may result in poor decisions and inadequate treatment. 
Pain treatment in particular is often neglected in torture survivors, particularly when the problem has been erroneously attributed to psychological etiology by health professionals unfamiliar with pain science.

It is rare in developed countries to see people sufficiently soon after torture that damage-specific, causal treatments with a higher likelihood of pain reliefs are possible. Prolonged and excessive healthcare utilization with referral to multiple specialists and repeated imaging and other examinations in order to identify tissuebased explanations for persistent pain should therefore be avoided. However, a standard pain assessment, with thorough clinical examination of the musculoskeletal system and neurological evaluation, is essential to identify potentially treatable disorders and possible pain-generating mechanisms. Proper assessment of the musculoskeletal system in torture survivors is time consuming, as most have been exposed to multiple forms of torture and may present with numerous pains and physical impairments. Knowledge of common methods of torture and of the likely mechanisms by which they produce pain is required for a systematic and effective examination. The pain history should include specific information about applied torture methods and onset of pain in relation to these; this information helps the clinician to ascertain possible damage to the musculoskeletal and peripheral nervous system and assess potential pain mechanisms. Various factors decrease the quality of the history: periods of unconsciousness; impaired memory; shame at disclosure, for instance, sexual assaults. Most torture survivors attribute the start of the pain to the torture, and describe that pain has continued, albeit usually with varying intensity; others describe remission of initial pain only for it to reappear later at high intensity and with a different quality. It is also important to ask patients about their beliefs about the pain, about damage done and about the causes and implications of their pain. In many cultures, pain is assumed to signal ongoing damage, and an explanation of mechanisms of persistent pain without damage enables patients to reframe pessimistic beliefs about the possibility of improved function, and to discuss changes in behavior that will promote rehabilitation.

As is recommended for chronic pain in general, an interdisciplinary, multimodal approach to pain management in survivors of torture is optimal, with a focus on agreed goals of improved understanding, function and participation. A structured approach to interdisciplinary rehabilitation therefore involves the following: identification of the problems and needs most relevant to the torture survivor; relating the problems to modifiable impairments, personal and environmental factors; and multimodal therapy delivered in a coordinated, problem-solving and individual-centered process with defined intervention targets for each professional member of the interdisciplinary team. Thus, in order to provide relevant interventions and outcomes, it is necessary to explore how the torture survivor with persistent pain experience and prioritize activities and participation. It can be difficult for torture survivors to accept the permanence of pain from their torture, to abandon hopes of complete relief and to accept that pain reduction and improvement in activity and societal level functioning are more realistic goals, implying consideration of physical, practical and psychological skills development. Survivors' expectations must therefore be addressed at the outset of treatment in any modality. Interdisciplinary pain management generally integrates education, psychological interventions targeting cognitive and behavioral aspects of adaptation to pain, physical therapy with the principal goal of enhancing overall physical functioning and reducing musculoskeletal impairment caused by the torture, and pharmacological treatment of pain and other.

There are no systematic studies of pharmacological treatment for chronic post-torture pain to suggest variation from best practice. As in other chronic pain conditions, pharmacological pain treatment should be based on thorough assessment and identification of pain mechanisms involved, and should aim not only to reduce pain but also to improve function and quality of life. Adherence to pharmacological treatment, including tolerance of side effects is often low, and accurate information is therefore essential. Particular attention should be paid to the possibility that torture survivors have been forcibly medicated in the past.

Exemplifying the above-mentioned, walking is a frequently prioritized problem among torture survivors 
exposed to falanga. An interdisciplinary, multimodal approach aimed at reducing the torture survivors selfdefined pain-related problem and increasing activity and participation could therefore include the following elements: pharmacological management (e.g., treatment with gabapentine for neuropathic pain); physiotherapy (e.g., treatment of overload injuries caused by a compensatory altered gait pattern and acquisition of appropriate footwear); and psychological intervention addressing behavioral and cognitive aspects of pain and pain-related disability.[Query-Q6: Alma Dabral(CE) to All(AU)]Could you please provide a Conclusion section which will be inserted before the future perspective section of your article?

Future perspective $\&$ call for research

Our understanding of persistent pain from torture is seriously lacking and research is needed in all areas. Such research is essential to advance theory development and improve outcome of intervention. Research in chronic post-torture pain should be clinically relevant as well as grounded in evidence and theory, focusing on pain mechanisms underlying chronic pain conditions following torture, and their relationships to torture methods applied and specific torture induced lesions. Pain treatment in torture populations should be recorded with systematic observation and broad outcome data in relation to clinical, functional, behavioral and psychosocial factors; even careful accounts of single cases can be heuristic. Development of effective assessment instruments across the various domains of torture-related pain and pain-related variables is a huge task but will be a prerequisite.

There are several reasons why evidence in this field is limited. Rehabilitation of torture survivors is largely carried out by health professionals working in humans right organizations and to date these services remain remote from mainstream healthcare provision, and focus on psychological rather than medical problems. Many of these organizations struggle for resources, and evaluation and research skills may not be represented among staff recruited to provide healthcare. Ideally, the skills of those who work with torture survivors would be combined with those of pain clinicians and researchers to build understanding and evaluate and improve the effectiveness of treatment and management interventions. [Query-Q7: Sankeetha Nadarajah(PE) to Kirstine Amris(AU)]Please provide titles for web references 1 and 2 (originally 54 and 55)

Disclaimer[Query-Q8: Alma Dabral(CE) to All(AU)]Please check and confirm that the disclosure section is correct.

This manuscript reflects only the author's views and none of the authors have any financial or other relationships that might lead to a conflict of interest with the content of this paper.

Financial \& competing interests disclosure

Gratitude is expressed to the OAK Foundation for the financial support of the Parker Institute. The authors have no other relevant affiliations or financial involvement with any organization or entity with a financial interest in or financial conflict with the subject matter or materials discussed in the manuscript apart from those disclosed.

No writing assistance was utilized in the production of this manuscript.

\section{References}

Papers of special note have been highlighted as:

- of interest; $\bullet$ of considerable interest

1. https://treaties.un.org/Pages/ViewDetails.aspx?src=TREATY\&mtdsg_no=IV-9\&chapter=4\&lang=en. 
2. www.ohchr.org/Documents/Issues/Torture/UNVFVT/GC/CAT-C-GC-3_en.doc.

3. Quiroga J, Jarason J. Politically-motivated torture and its survivors: a desk study of the literature. Torture 16(2-3) (2005).

- Comprehensive literature review describing the work field of torture.

4. Jaranson JM, Quiroga J. Evaluating the services of torture rehabilitation programmes: history and recommendations. Torture 21(2), 98-140 (2011).

- Comprehensive literature review assessing specialized rehabilitation services for torture survivors world wide.

5. Mollica RF. Medical best practices for the treatment of torture survivors. Torture 21(1), $8-17$ (2011).

6. Neuner F, Kurreck S, Ruf M, Odenwald M, Elbert T, Schauer M. Can asylum-seekers with posttraumatic stress disorder be successfully treated? A randomized controlled pilot study. Cogn Behav. Ther. 39(2), 81-91 (2010).

7. Amris K, Williams A. Chronic pain in survivors of torture. Pain Clinical Update 15(7), (2007).

- Describes chronic pain in survivors of torture from a clinical perspective.

8. Taylor B, Carswell K, Williams AC. The interaction of persistent pain and post-traumatic reexperiencing: a qualitative study in torture survivors. J. Pain Symptom Manage. 46(4), 546-555 (2013).

9. Williams A, Amris K. Pain from torture. Pain 133(1-3), 5-8 (2007).

10. Lumley MA, Cohen JL, Borszcz GS et al. Pain and emotion: a biopsychosocial review of recent research. J. Clin. Psychol. 67(9), 942-968 (2011).

11. Basoglu M. A multivariate contextual analysis of torture and cruel, inhuman, and degrading treatments: implications for an evidence-based definition of torture. Am. J. Orthopsychiatry 79(2), 135-145 (2009).

12. Basoghu M, Livanou M, Crnobaric C. Torture vs other cruel, inhuman, and degrading treatment: is the distinction real or apparent? Arch. Gen. Psychiatry 64(3), 277-285 (2007).

13. Olsen D, Montgomery E, B'jholm S, Foldspang S. Prevalent musculoskeletal pain as a correlate of previous exposure to torture. Scand. J. Public Health 34, 496-503 (2006).

14. Rasmussen O. Medical aspects of torture. Dan. Med. Bull. 37(Suppl.1), 1-88 (1990).

- The first medical thesis on health-related consequences of torture.

15. Westermeyer J, Hollifield M, Spring M, Johnson D, Jaranson J. Comparison of two methods of inquiry for torture with East African refugees: single query versus checklist. Torture 21(3), 155-172 (2011).

16. Williams AC, Pena CR, Rice AS. Persistent pain in survivors of torture: a cohort study. J. Pain Symptom Manage. 40(5), 715-722 (2010). 
17. Eisenman DP, Gelberg L, Liu H, Shapiro MF. Mental health and health-related quality of life among adult Latino primary care patients living in the United States with previous exposure to political violence. JAMA 290(5), 627-634 (2003).

18. Burnett A, Peel M. Asylum seekers and refugees in Britain. The health of survivors of torture and organised violence. BMJ 322(7286), 606-609 (2001).

19. Crosby SS, Norredam M, Paasche-Orlow MK, Piwowarczyk L, Heeren T, Grodin MA. Prevalence of torture survivors among foreign-born patients presenting to an urban ambulatory care practice. J. Gen. Intern. Med. 21(7), 764-768 (2006).

20. O'Connor M. Can we prevent doctors being complicit in torture? Breaking the serpent's egg. J. Law Med. 17(3), 426-438 (2009).

21. Sonntag S. Doctors' involvement in torture. Torture 18(3), 161-175 (2008).

22. Gorst-Unsworth C, Goldenberg E. Psychological sequelae of torture and organised violence suffered by refugees from Iraq. Trauma-related factors compared with social factors in exile. Br. J. Psychiatry 172, 90-94 (1998).

23. Steel Z, Silove D, Brooks R, Momartin S, Alzuhairi B, Susljik I. Impact of immigration detention and temporary protection on the mental health of refugees. Br. J. Psychiatry 188, 58-64 (2006).

24. Olsen D, Montgomery E, Carlsson J, Foldspang S. Prevalent pain and pain level among torture survivors. Dan. Med. Bull. 53, 210-214 (2006).

25. Dülgeroglu D. Pathology of the musculoskeletal system occurring after torture. Annual Report 2000 of Human Rights Foundation of Turkey, 41-47 (2000).

[Query-Q9: Alma Dabral(CE) to All(AU)]Please could you provide volume number in reference 23, as we are unable to find it on the Internet?

26. Olsen D, Montgomery E, B'jholm S, Foldspang S. Prevalence of pain in the head, back and feet in refugees previously exposed to torture: A ten-year follow-up study. Disability and Rehabilitation 29(2), 163-171 (2007).

27. Morville AL, Amris K, Eklund M, Danneskiold-Samsoe B, Erlandsson LK. A longitudinal study of changes in asylum seekers ability regarding activities of daily living during their stay in the asylum center. $J$. Immigr. Minor. Health (2014).

28. Danneskiold-Samsoe B, Bartels E, Genefke I. Treatment of torture victims - a longitudinal clinical study. Torture 17(1), 11-17 (2007).

29. Amris K. Chronic pain in survivors of torture - psych or soma? In: Torture and Organised Violence. Contributions to a Professional Human Rights Response. Berliner P, Arenas J, Haagensen J (Eds). Dansk Psykologisk Forlag, Denmark, 31-69 (2005).

30. Musisi S, Kinyanda E, Liebling H, Mayengo-Kiziri R. Post-traumatic torture disorders in Uganda. Torture 10, 81-87 (2000).

31. Rasmussen $\mathrm{O}$, Amris S, Blaauw M, Danielsen L. Medical physical examination in connection with torture: section II. Torture 15(1), 37-45 (2005). 
32. Thomsen A, Eriksen J, Scmidt-Nielsen K. Chronic pain in torture survivors. Forensic Sci. Int. 108(3), 155-163 (2000).

33. Edston E. The epidemiology of falanga - incidence among Swedish asylum seekers. Torture 19(1), 27-32 (2009).

34. Prip K, Persson AL. Clinical findings in men with chronic pain after falanga torture. Clin. J. Pain 24(2), 135-141 (2008).

35. Prip K, Persson AL, Sjolund BH. Self-reported activity in tortured refugees with long-term sequelae including pain and the impact of foot pain from falanga - a cross-sectional study. Disabil. Rehabil. 33(7), 569-578 (2011).

36. Amris K, Torp-Pedersen S, Rasmussen OV. Long-term consequences of falanga torture - what do we know and what do we need to know? Torture 19(1), 33-40 (2009).

37. Savnik A, Amris K, Rogind $\mathrm{H}$ et al. MRI of the plantar structures of the foot after falanga torture. Eur. Radiol. 10(10), 1655-1659 (2000).

38. Torp-Pedersen S, Amris K, Holm CC, Konig M, Prip K, Danneskiold-Samsoe B. Vascular response to ischemia in the feet of falanga torture victims and normal controls - color and spectral Doppler findings. Torture 19(1), 12-18 (2009).

39. Prip K, Persson AL, Sjolund BH. Pain when walking: individual sensory profiles in the foot soles of torture victims - a controlled study using quantitative sensory testing. BMC. Int. Health Hum. Rights. 12 , 40 (2012).

40. Prip K, Persson AL, Sjolund BH. Sensory functions in the foot soles in victims of generalized torture, in victims also beaten under the feet (falanga) and in healthy controls - a blinded study using quantitative sensory testing. BMC. Int. Health Hum. Rights. 12, 39 (2012).

41. Moreno A, Grodin M. Torture and its neurological sequelae. Spinal Cord 40(5), 213-223 (2002).

42. Woolf CJ. Central sensitization: implications for the diagnosis and treatment of pain. Pain 152(3 Suppl.), S2-S15 (2011).

43. Gurr R, Quiroga J. Approaches to torture rehabilitation. A desk study covering effects, costeffectiveness, participation, and sustainability. Torture 11(Suppl. 1) (2001).

44. Campbell TA. Psychological assessment, diagnosis, and treatment of torture survivors: a review. Clin. Psychol. Rev. 27(5), 628-641 (2007).

45. Summerfield D. The invention of post-traumatic stress disorder and the social usefulness of a psychiatric category. BMJ 322(7278), 95-98 (2001).

46. Jayatung M. Psychological effects of torture. Groundviews, journalism for citizens, peace and conflict, 15 April (2010).

[Query-Q10: Alma Dabral(CE) to All(AU)]Please provide complete publication details in reference 44 as we are unable to find it on the Internet.

47. Williams AC, Volkmann AM. Understanding pain from torture: cultural considerations. Pain

Management 3, 359-366 (2010). 
48. Carlsson JM, Mortensen EL, Kastrup M. Predictors of mental health and quality of life in male tortured refugees. Nord. J. Psychiatry 60(1), 51-57 (2006).

49. Porter M, Haslam N. Predisplacement and postdisplacement factors associated with mental health of refugees and internally displaced persons: a meta-analysis. JAMA 294(5), 602-612 (2005).

50. Patel N, Kellezi B, Williams AC. Psychological, social and welfare interventions for psychological health and well-being of torture survivors. Cochrane Database of Syst. Rev. 11 (2014). [Query-Q11: Alma Dabral(CE) to All(AU)]Please could you provide volume number in reference 48, as we are unable to find it on the Internet?

51. Robjant K, Fazel M. The emerging evidence for narrative exposure therapy: a review. Clin. Psychol. Rev. 30(8), 1030-1039 (2010).

52. McFarlane CA, Kaplan I. Evidence-based psychological interventions for adult survivors of torture and trauma: a 30-year review. Transcult. Psychiatry 49(3-4), 539-567 (2012).

53. Nickerson A, Bryant RA, Silove D, Steel Z. A critical review of psychological treatments of posttraumatic stress disorder in refugees. Clin. Psychol. Rev. 31(3), 399-417 (2011).

- Highlights the distinctive challenges to traditional trauma-focused treatments of refugees with post-traumatic stress.

54. Mundt A, Wunsch P, Heinz A, Pross C. Evaluating interventions for posttraumatic stress disorder in low and middle income countries: narrative exposure therapy. Interventions 12(2), 250-266 (2014).

55. Sjohund BH, Kastrup M, Montgomery E, Persson AL. Rehabilitating torture survivors. J. Rehabil. Med. 41(9), 689-696 (2009). 